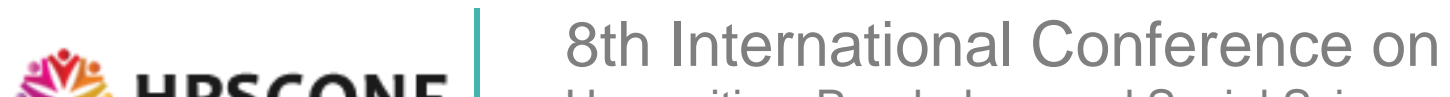 HPSCONF

\section{Philosophy for the Body, Food for the Mind}

\begin{abstract}
:
Ancient Greek philosophers stressed the importance of asceticism, in order to increase wisdom, sometimes reaching the point of starvation. Neglecting one's own body by strict ascetic practices, which included a very poor and limited diet, led to a higher status at the philosophical level and was a way to ideal perfection. Food or rather the refusal of it played a crucial role in their philosophy. Ancient biographers tell us about this struggle against material needs, whereas at the same time some comic texts bear witness to the contrast with ordinary people's way of eating. When Christianity took over ancient civilization and became the dominant ideology, the ideal of perfection focused on salvation and union with God. In order to attain this divine union, which recalled the original perfection before sin, all passions should be controlled, especially sex and food. Depriving the body from almost any nourishment was the safest way to attain a full development of the soul and a perfect knowledge of God. In the West, the ideal of perfection has changed throughout history up to the present, from ancient philosophy to spiritual salvation, purity or even aesthetic excellence, all of which are subjective concepts of perfection to be attained by individuals through despising material food, sometime to the point of starvation.
\end{abstract}

Keywords: Ancient Greek Philosophy; Asceticism; Biographies; Diogenes Laertius; Women Saints

\section{Rev. Abhijit Chowdhury}

Siddharth Buddha Vihar Trust,

Guatam Buddha Nagar, Balkan-JI Barl,

Khemani Road, Ulhasnagar-421003,

Thane, Maharashtra, India. 